\title{
ACTIVITY DENSITY OF CARABID BEETLES ALONG AN URBANISATION GRADIENT
}

\author{
Simone Fattorini ${ }^{1, *}$, Cristina Mantoni ${ }^{1}$, Davide Bergamaschi ${ }^{2}$, Lorenzo Fortini ${ }^{3}$ \\ Francisco J. Sánchez ${ }^{3}$, Letizia Di Biase ${ }^{1}$ and Andrea Di Giulio ${ }^{3}$ \\ ${ }^{1}$ Department of Life, Health and Environmental Sciences, University of L'Aquila \\ Via Vetoio, 67100, Coppito, L'Aquila, Italy \\ E-mails: simone.fattorini@univaq.it; https://orcid.org/0000-0002-4517-2135 \\ cristina.mantoni@graduate.univaq.it; https://orcid.org/0000-0002-1981-0842 \\ letizia.dibiase@graduate.univaq.it; https://orcid.org/0000-0001-5675-2904 \\ ${ }^{2}$ Department of Entomology, University of Arizona, Tucson, Arizona, USA \\ E-mail: davbergamaschi@email.arizona.edu; https://orcid.org/0000-0001-8903-5151 \\ ${ }^{3}$ Department of Science, University of Roma Tre, Viale G. Marconi 446, 00146, Roma, Italy \\ E-mails: lorenzo_fortini@alice.it; https://orcid.org/0000-0003-3324-9278 \\ 28csjf@gmail.com; https://orcid.org/0000-0003-2242-8641 \\ andrea.digiulio@uniroma3.it; https://orcid.org/0000-0003-0508-0751
}

Several works have investigated the impact of urbanisation on carabid activity density using urban-rural gradients. Such works compared activity density recorded from green spaces located in different parts of a city and assigned to categories of increasing urban intensity, which poses two problems: (1) since the gradient is divided into categories, it is impossible to model continuous variations in biotic responses, and (2) sites representative of different urbanisation levels are not true segments of the same ecological continuum. To surpass these problems, we modelled variations in carabid activity density along an urbanrural transect within a single green space extending from the city centre of Rome to rural environments. Carabids were sampled by pitfall traps from sites distributed along the entire gradient. We used breakpoint regressions to model how (1) carabid activity density, (2) carabids/beetles ratio, (3) carabids/insects ratio and (3) carabids/arthropods ratio varied along the gradient. As already observed for various organisms in urban environments, we found that activity density of carabids and their contribution to the abundance of beetles, insects and arthropods, peaked in the middle of the gradient. This supports the intermediate disturbance hypothesis, according to which moderate urbanisation may favour diversity by increasing habitat heterogeneity.

Keywords: Coleoptera, Carabidae, abundance, urban-rural gradient, urban ecology, Italy.

\section{INTRODUCTION}

Increasing urbanisation is considered a major threat to biodiversity (McKinney 2002, 2006, McDonald et al. 2013). On the other hand, urban areas offer many opportunities for biodiversity conservation. First, the high human density in urban areas allows a reduction of anthropogenic pressures on natural ecosystems and improves the efficiency of resources uses (WoRldWATch Institute 2007, McDonald et al. 2013), making urban areas "our last best hope 
for a sustainable future" (ELDREDGe \& Horenstein 2014). Second, the presence of green spaces within cities may play important roles for the conservation of many species, including threatened ones (ANGOlD et al. 2006, Jones \& LeATHER 2012, Adler \& Tanner 2013, Forman 2014, Fattorini \& Galassi 2016). Animal and plant responses to urbanisation are, however, extremely variable: some taxa are negatively affected, others are favoured (McKinnEy 2008, FATTORINI 2011, 2019).

Among invertebrates, carabid beetles (Coleoptera Carabidae) are one of the best-investigated groups in urban ecology (Niemelä \& Kötze 2009, Jones \& Leather 2012, New 2015). Most research has been focused on the response of carabids to increasing urbanisation by referring to the concept of the urbanrural gradient. In most cities, urbanisation intensity tends to decrease from the city centre to the most peripheral areas (McKinney 2008, Forman 2014). Thus, 'distance from city centre' is the most commonly used measure for expressing the gradient and selecting sampling stations along with it (New 2015). This spatial gradient is associated with variation in many abiotic and biotic factors, such as human population density, housing density, proportion of impervious surfaces, soil compaction, proportion of natural areas, atmospheric pollution, temperatures, incidence of native species, incidence of alien species, etc. (McDonnell \& Hahs 2008, Fattorini 2019). Research on the influence of urbanisation on carabid communities has been mostly focused on variation in species richness and population abundances along the gradient (Niemelä \& Kötze 2009, Jones and Leather 2012, New 2015). Since carabids are usually sampled using pitfall traps, which collect surface-active grounddwelling animals, the number of collected individuals is in fact a function of both true population density and carabid movement on the soil surface. Thus, most research on carabid ecology uses measures of activity density to express how carabids respond to changes in environmental characteristics (FRENCH et al. 2001, Purtauf et al. 2005, Lafage et al. 2014).

Variation in carabid activity density along the urban-rural gradient may follow different patterns. The most commonly observed pattern seems to be an increase in activity density from the most urbanised areas to the rural areas, which is consistent with the idea that urbanisation has negative effects on most species (Niemelä et al. 2002, New 2015). However, a hump-shaped pattern, with the activity density peaking at the middle of the gradient, is also common (Niemelä \& Kötze 2009). This pattern can be interpreted in the context of the 'intermediate disturbance hypothesis' (Connell 1978), in the form of the disturbance heterogeneity model (PorTer et al. 2001), since an intermediate urbanisation might increase habitat heterogeneity and hence resources diversity and abundance (FATTORINI 2019). A decrease in activity density from the most to least urbanised areas seems an uncommon situation (NIEMEL $\ddot{A} \&$ 
Köтze 2009) and might be due to the strong impact of the most tolerant species (FATtorini 2019).

Available studies on carabid responses to the urban-rural gradient typically compared values of activity density recorded from different green spaces assigned to different classes of increasing urban intensity, usually indicated as "urban", "suburban", and "rural" (Niemelä \& Kötze 2009, New 2015). This approach has two important limits. First, the gradient is divided into categories and, therefore, it is impossible to model patterns of continuous variation along the gradient. Second, because the green spaces selected as representative of the different levels of urbanisation are located in different parts of the city, they are not true segments of the same ecological continuum but may reflect a variety of conditions that cannot be subsumed by a hypothetically unique gradient.

Rome (Italy) is a large city with an ancient history of urbanisation, yet approximately half of its area is occupied by green spaces of various size and characterised by different ecological setting and forms of management. Some of the largest green spaces are remnants of the former rural ecomosaic known as "campagna romana", a landscape of unrivalled historical and cultural importance (Celesti Grapow \& Fanelli 1993, Lucchese \& Pignatti 2009). Among them, particularly important is the "Parco Regionale dell'Appia Antica" (Appian Way Regional Park), the largest green space in Rome, extending from the city centre (where most of the park is embedded in a densely built-up matrix) to the borders of the city (where the park enters into the "campagna romana" rural landscape). This peculiar situation offers the intriguing opportunity of investigating an urban-rural gradient within a single green space, thus surpassing the problems mentioned above associated with the use of different green spaces. For this reason, we started a research project using this green space to study how carabids respond to the urban-rural gradient. To the best of our knowledge, our research is the first that considered an urban-rural gradient within a single green space. In particular, in the present paper, we investigated how total carabid activity density varies along the urban-rural gradient. We also investigated spatial variations in the contribution of carabid abundance to the beetle, insect and arthropod communities along the gradient.

\section{METHODS}

\section{Study area}

With about 3 million inhabitants, Rome is the largest Italian city and ranks third among those of the European Union, after Berlin and Madrid. Urban Rome is usually defined as the territory of the city encompassed by the great motorway ring (Grande Raccordo Anulare, GRA) that circumscribes an area of about $360 \mathrm{~km}^{2}$ (see FATTORINi 2011, 
Di Pietro et al. 2020). The Appia Antica Regional Park ( $\left.41^{\circ} 50^{\prime} 00^{\prime \prime} \mathrm{N}-12^{\circ} 33^{\prime} 00^{\prime \prime} \mathrm{E}\right)$ is a protected area of about 4,580 hectares, extending from the city centre of Rome to the neighbouring rural areas of Colli Albani (Fig. 1). The protected area includes archaeological zones along the ancient Appian Way, from the centre of Rome to the 10th Mile, including the Villa of the Quintilii and the Tombs of Via Latina. The park also includes two other smaller protected areas, the Caffarella Park and the Park of the Aqueducts.

The Appia Antica Regional Park includes a mosaic of cultivated fields and uncultivated areas with different degrees of naturalness. The landscape is dominated by meadows and, to a lesser extent, by scrublands. Vegetation is mainly represented by the Mediterranean maquis (with Pistacia lentiscus, Rhamnus alaternus, and Euonimus europaeus). Due to the millenary human presence, ruderal species (such as Sonchus asper, Pteridium aquilinus, and Cymbalaria muralis), as well as cultivated species (especially Olea europaea and Prunus dulcis), are widespread. The area also incorporates fragments of wet meadows and ponds, and, along with watercourses, strips of riparian vegetation with poplars (Populus nigra), willows (Salix alba), and field elms (Ulmus minor). Detailed information on the vegetation of the study area can be found in Buccomino and STANisci (2000) and CESCHIN et al. (2006).

\section{Carabid sampling}

Within the study area, we designed a transect of about $8 \mathrm{~km}$. Along the transect, we identified 9 sampling points at increasing distance from the city centre (Fig. 1): the closest site was at about $5.5 \mathrm{~km}$ from the city centre and was surrounded mainly by built-up areas (minimum distance from buildings: $300 \mathrm{~m}$ ), the farthest site was at about $12 \mathrm{~km}$, and it is near the GRA, i.e. at the borders of the city. A minimum distance of $500 \mathrm{~m}$ separated sampling sites.

Pitfall traps consisted of clear plastic cups (diameter: $9.5 \mathrm{~cm}$, depth: $15 \mathrm{~cm}$ ) sunk in

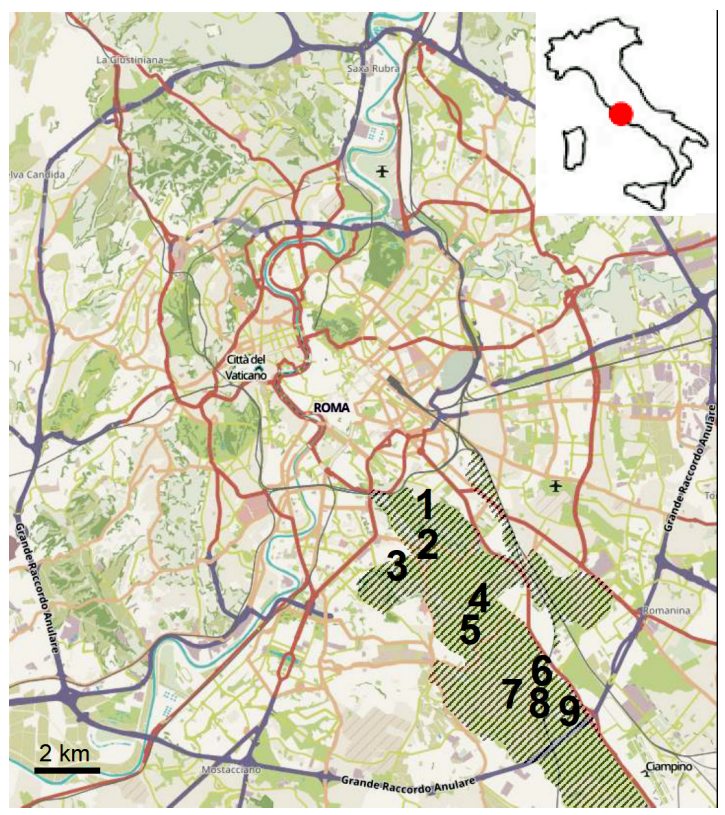
the ground with the cup-lip level with the soil surface and covered by sloped stones to limit the rainwater influx and capture of non-target taxa. Covering stones were elevated 5-7 $\mathrm{cm}$ above the ground using four smaller stones at their corners. Each trap was filled with $250 \mathrm{~mL}$ of beer with salt, with a drop of unscented detergent to break the surface tension. The number of pitfall traps varied among sites, from a minimum of 3 traps to a maximum of 16

Fig. 1. Map of urban Rome with location of the study area (the Appia Antica Regional Park, dashed area) and sampling sites (numbers: 1-9). Map based on the Humanitarian layer of OpenStreetMap (C) OpenStreetMap contributors): https:// www.openstreetmap.org/copyright/en 
traps, depending on site habitat heterogeneity. Moreover, the number of available traps per site varied because of trap damage and trap loss. Traps within sites were placed at random and separated by at least 10 meters from each other, to ensure independent sampling (Niemelä \& KötZe 2009).

Sampling was conducted in four autumn sampling periods (from 18th October to 6th December) and four spring sampling periods (from 7th May to 24th June). Each sampling period lasted about ten days. We used this temporal distribution of sampling periods at the turn of two consecutive years because Mediterranean spring climatic conditions and hence biotic responses, recorded in a given spring-summer, are strongly influenced by those of the previous autumn-winter (FANFANi et al. 2014). Moreover, this sampling strategy allowed the estimation of activity density that included both autumn and spring breeders (see Paarman 1970, Hůrka 1986, Den Boer \& Den Boer-Danjje 1990, Brandmayr et al. 2005). For each trapping period, traps were active for a minimum of 7 days to a maximum of 12. Variation in trapping duration and time between trapping sessions was due to unstable weather conditions. Upon collection, trap content was rinsed with water and stored in vials with $70 \%$ ethanol.

\section{Data analysis}

Because the number of active traps and time of their functioning varied among sites and sampling periods, we standardised carabid abundance as activity density (AD). AD was calculated as the number of collected carabids divided by the sampling effort, expressed as the number of traps $\times$ number of days $/ 10$ (Pizzolotro et al. 2018). For each site, we calculated the carabid activity density for the two sampling periods separately (autumn and spring $\mathrm{AD}$ values) and combined (total AD).

We also calculated, for each site and sampling period, the following proportions (percentages) to express the relative contribution of carabids to the local abundance of soil surface-active animals: CARCOL $=$ Number of Carabidae/Total number of Coleoptera; CARINS $=$ Number of Carabidae/Total number of Insecta; CARART $=$ Number of Carabidae/Total number of Arthropoda. Although pitfall traps might be less efficient for arthropods different from carabids, these values can be considered as rough estimates of the contribution of carabid activity density to the overall activity density of soil dwelling animals that, at each taxonomic level, have similar behaviours.

To test if $\mathrm{AD}$ values had similar spatial variations between seasons, we correlated site AD values recorded from the two periods by using a Spearman rank correlation coefficient. The same approach was used to test if values of CARCOL, CARINS and CARART showed similar patterns between seasons.

To test if average (median) carabid $\mathrm{AD}$ values varied between seasons, we compared the average (median) AD values from the two sampling periods by using Wilcoxon tests for paired samples. The same approach was used to test if average (median) CARCOL, CARINS and CARART values varied between periods.

To model how activity density varied along the urban-rural gradient, we calculated the distance of each sampling site from the city centre. "Distance from city centre" is a common parameter of defining gradients or selecting sampling stations along with them when taken to correspond with the degree of urbanisation (New 2015). Namely, we measured the distance of each pitfall trap from the city centre and then calculated the average distance of the pitfall traps belonging to the same site as the "site distance" (D). Distances were 


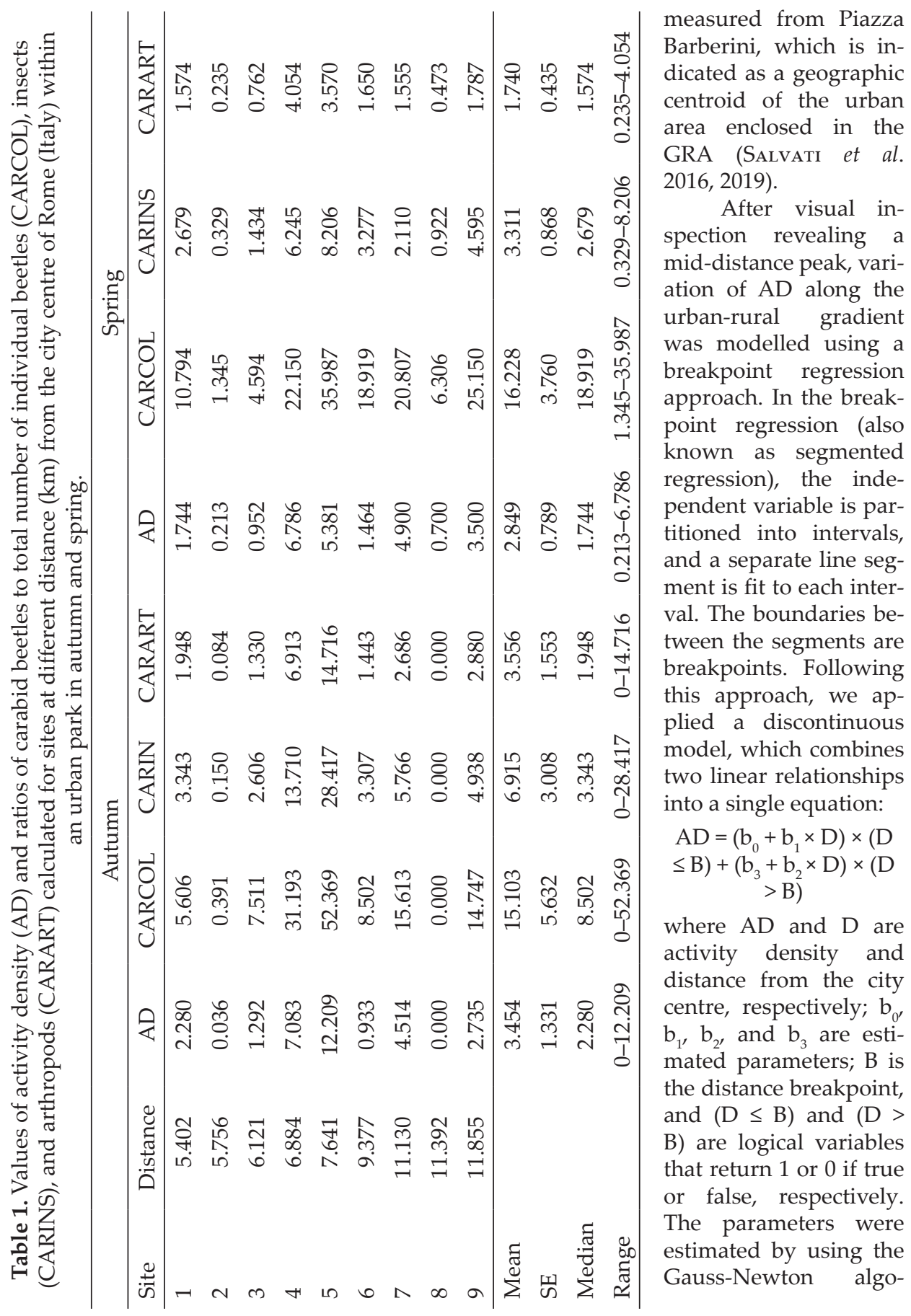


rithm. The breakpoint was set at $8 \mathrm{~km}$, corresponding to the middle of the gradient. The same approach was used to model spatial variations in CARCOL, CARINS and CARART values. Spearman and Wilcoxon tests were conducted using PAST 4.01 (HAmmer et al. 2001), whereas breakpoint regressions were done in STATISTICA v. 6.0 (STATSoft Inc. 2001).

\section{RESULTS}

We collected 683 Carabidae, 5,311 Coleoptera, 11,565 Insecta, and 21,571 Arthropoda in autumn, and 630 Carabidae, 4,351 Coleoptera, 20,693 Insecta, and 35,296 Arthropoda in spring, for a total of 1,313 Carabidae, 9,662 Coleoptera, 32,258 Insecta, and 56,867 Arthropoda. Carabidae represented about $12.9 \%$ of beetles, $5.9 \%$ of insects, and 3.2\% of arthropods in autumn, and $14.5 \%$ of beetles, $3.0 \%$ of insects, and $1.8 \%$ of arthropods in spring. Overall, carabids accounted for $13.6 \%$ of beetles, $4.1 \%$ of insects and $2.3 \%$ of arthropods.

We found no significant difference in median $\mathrm{AD}$ values between seasons (Wilcoxon paired test; Tables $1 \& 2$ ). Similarly, we did not find significant differences between seasons in median values (Wilcoxon paired test) of CARCOL, CARINS and CARART (Tables 1 \& 2). AD values in autumn followed the same spatial pattern recorded in spring (Spearman rank correlation test; Table 2, Fig. 2). Similarly, spatial patterns of CARCOL, CARINS and CARA$\mathrm{RT}$ values in autumn were correlated (Spearman rank correlation test) with those observed in spring (Table 2, Fig. 2).

Breakpoint regressions (Table 3, Fig. 3) revealed that AD, CARCOL, CARINS, and CARART increased significantly from the beginning to the middle of the gradient, where a peak was detected in all cases (first regression segment). The second regression segment was not significant in all cases. However, in the case of $\mathrm{AD}$, the slope $\left(\mathrm{b}_{2}\right)$ of the second regression was relatively high, suggesting a possible positive trend.

Table 2. Results of tests for differences (Wilcoxon paired test) and correlations (Spearman test) in activity density (AD) and ratios of carabid beetles to total number of individual beetles (CARCOL), insects (CARINS), and arthropods (CARART) between seasons (autumn versus spring) for nine sites within an urban park at different distance from the city centre of Rome (Italy). $W=$ Wilcoxon statistic; $r_{\mathrm{s}}=$ Spearman rank correlation coefficient; $p=$ probability. $N=9$ in all cases.

\begin{tabular}{lcccc}
\hline & \multicolumn{2}{c}{ Differences between medians } & \multicolumn{2}{c}{ Correlations } \\
\cline { 2 - 5 } & $W$ & $p$ & $r_{\mathrm{s}}$ & $p$ \\
\hline $\mathrm{AD}$ & 25 & 0.767 & 0.950 & $<0.001$ \\
CARCOL & 28 & 0.515 & 0.867 & 0.005 \\
CARINS & 38 & 0.066 & 0.867 & 0.005 \\
CARART & 38 & 0.066 & 0.900 & 0.002 \\
\hline
\end{tabular}


Table 3. Results of breakpoint regressions of activity density (AD) and ratios of carabid beetles to total number of individual beetles (CARCOL), insects (CARINS), and arthropods (CARART) as a function of distance from the city centre of Rome (Italy) (in km). $\mathrm{b}_{0^{\prime}}$ $b_{1}, b_{2}$, and $b_{3}$ are estimated parameters.

\begin{tabular}{ccccc}
\hline & Estimate & Standard Error & t-value & p-level \\
\hline AD & & & & \\
$\mathrm{b}_{0}$ & -20.119 & 7.088 & -2.839 & 0.036 \\
$\mathrm{~b}_{1}$ & 3.748 & 1.105 & 3.391 & 0.019 \\
$\mathrm{~b}_{3}$ & -4.039 & 11.666 & -0.346 & 0.743 \\
$\mathrm{~b}_{2}$ & 0.585 & 1.063 & 0.551 & 0.606 \\
CARCOL & & & & \\
$\mathrm{b}_{0}$ & -104.960 & 28.368 & -3.700 & 0.014 \\
$\mathrm{~b}_{1}$ & 19.178 & 4.424 & 4.335 & 0.007 \\
$\mathrm{~b}_{3}$ & 6.481 & 46.693 & 0.139 & 0.895 \\
$\mathrm{~b}_{2}$ & 0.624 & 4.253 & 0.147 & 0.889 \\
CARINS & & & & \\
$\mathrm{b}_{0}$ & -34.322 & 8.747 & -3.924 & 0.011 \\
$\mathrm{~b}_{1}$ & 6.308 & 1.364 & 4.624 & 0.006 \\
$\mathrm{~b}_{3}$ & 2.777 & 14.398 & 0.193 & 0.855 \\
$\mathrm{~b}_{2}$ & 0.010 & 1.311 & 0.008 & 0.994 \\
CARART & & & & \\
$\mathrm{b}_{0}$ & -15.838 & 4.387 & -3.611 & 0.015 \\
$\mathrm{~b}_{1}$ & 2.964 & 0.684 & 4.332 & 0.007 \\
$\mathrm{~b}_{3}$ & 1.403 & 7.220 & 0.194 & 0.854 \\
$\mathrm{~b}_{2}$ & 0.007 & 0.658 & 0.011 & 0.991 \\
\hline
\end{tabular}

\section{DISCUSSION}

Activity density of carabids in urban Rome showed similar values in autumn and spring. Carabid phenology is known to vary geographically in response to different climatic conditions (Thiele 1977, Brandmayr \& Zetto 1986, Betz 1992, Holland 2002). Under Mediterranean climate, lowland carabid communities appear to have two peaks of activity: a first, usually higher, peak in autumn (with a prevalence of autumn breeders) and a second, usually lower peak in spring (Comandini \& Vigna Taglianti 1990). Our results indicate that overall activity density in spring did not differ significantly from that recorded in autumn. This can be explained by assuming either a constant activity density over the year (as recorded by Brandmayr \& ZetTo 1986 in 
the lowland Mediterranean belt on the Triestine Karst) or the presence of two similar peaks. In this second circumstance, the spring peak might be similar to the autumn peak, and not lower as proposed by Comandini and Vigna TAglianti (1990).

In both seasons, spatial patterns of activity density showed their maximum in the middle of the gradient, which indicates that variations in climate conditions did not change the AD spatial patterns. Our analyses based on total AD values indicate that activity density increased linearly from the beginning of the transect (i.e. in the portion of the park near the city centre) to the middle, at about $7-8 \mathrm{~km}$ from the city centre. This result contrasts with previous research on urban carabids showing a peak for rural areas (five cases out of the eight reported in Niemelä \& Kötze 2009), but is consistent with others indicating a peak in suburban areas (three cases out of the eight reported in Niemelë \& Kötze 2009). In fact, the eight urban-rural gradients investigated by Niemelä and Kötze (2009) divided each gradient into three zones (urban,
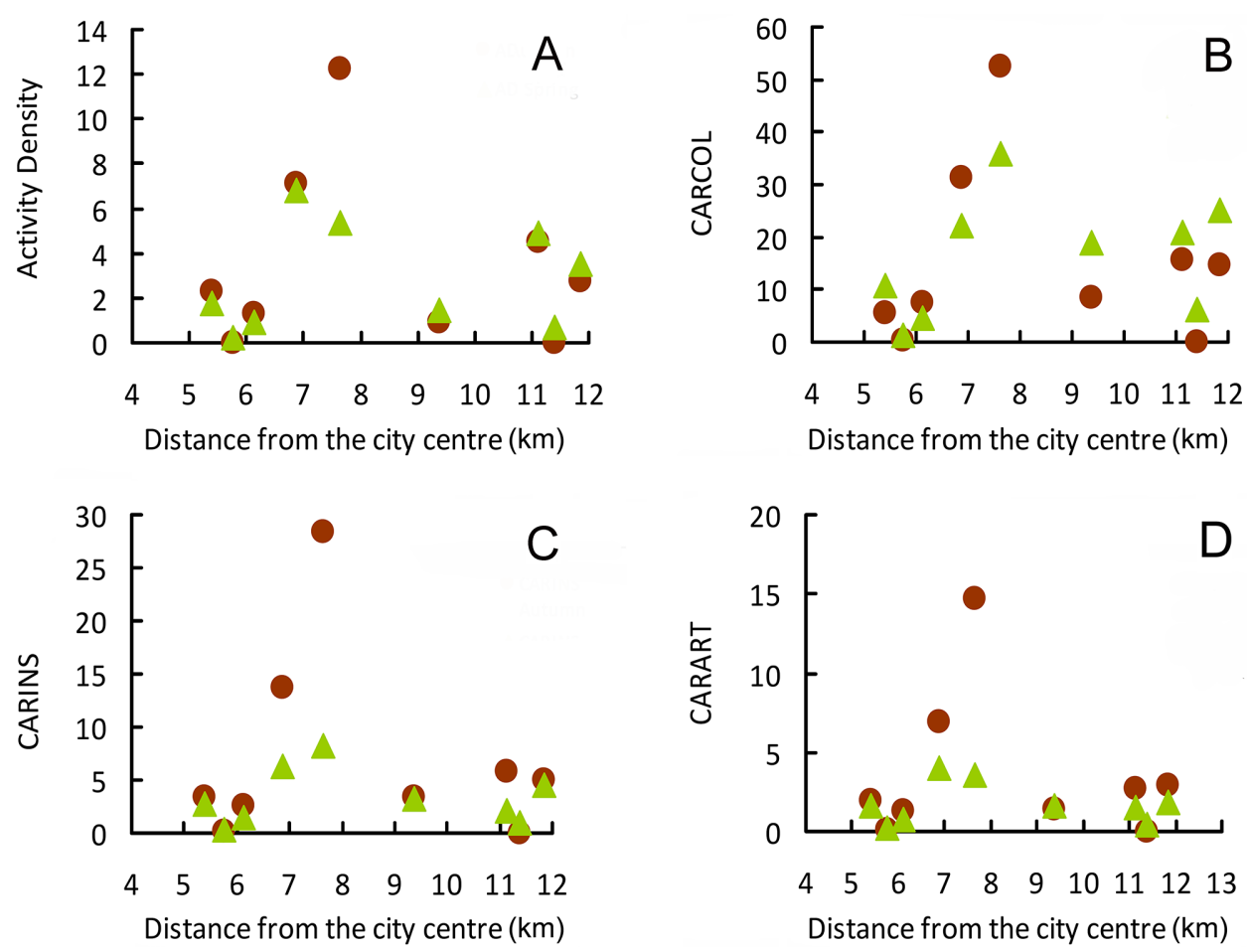

Fig. 2. Spatial variation in activity density $(A D$, panel $A)$ and ratios of carabid beetles to total number of individual beetles (CARCOL, panel B), insects (CARINS, panel C), and arthropods (CARART, panel D) along the urban gradient ( $\mathrm{km}$ from the city centre) in autumn (brown cricles) and spring (green triangles) 
suburban, rural) and compared activity density between them. Moreover, these three zones were identified, for each gradient, in different parts of the city characterised by different urbanisation intensity. Our approach allowed a more detailed analysis because we did not compare zones at different urbanisation intensity, but modelled a continuous spatial gradient within the same green area from the city centre to rural areas at the border of the city.

More in general, our results are consistent with previous research reporting high species abundance values in the middle of the urban-rural gradient. For example, among vertebrates, BLAIR (1999) reported a peak in bird abundance with intermediate urbanisation levels, while Eötvös et al. (2020) found a higher predation pressure by ground active arthropods on sentinel prey in moderately disturbed suburban forest habitats, which is consistent with a higher activity density of these predators.

This middle peak can be explained by the disturbance heterogeneity model of species richness proposed by PORTER et al. (2001). According to this model, a diversity peak in the middle of the gradient is the result of high habitat heterogeneity due to a combination of native and anthropogenic habitats. Connell's (1978) original formulation of the intermediate disturbance hypothesis proposes that in a community left undisturbed competitive exclusion
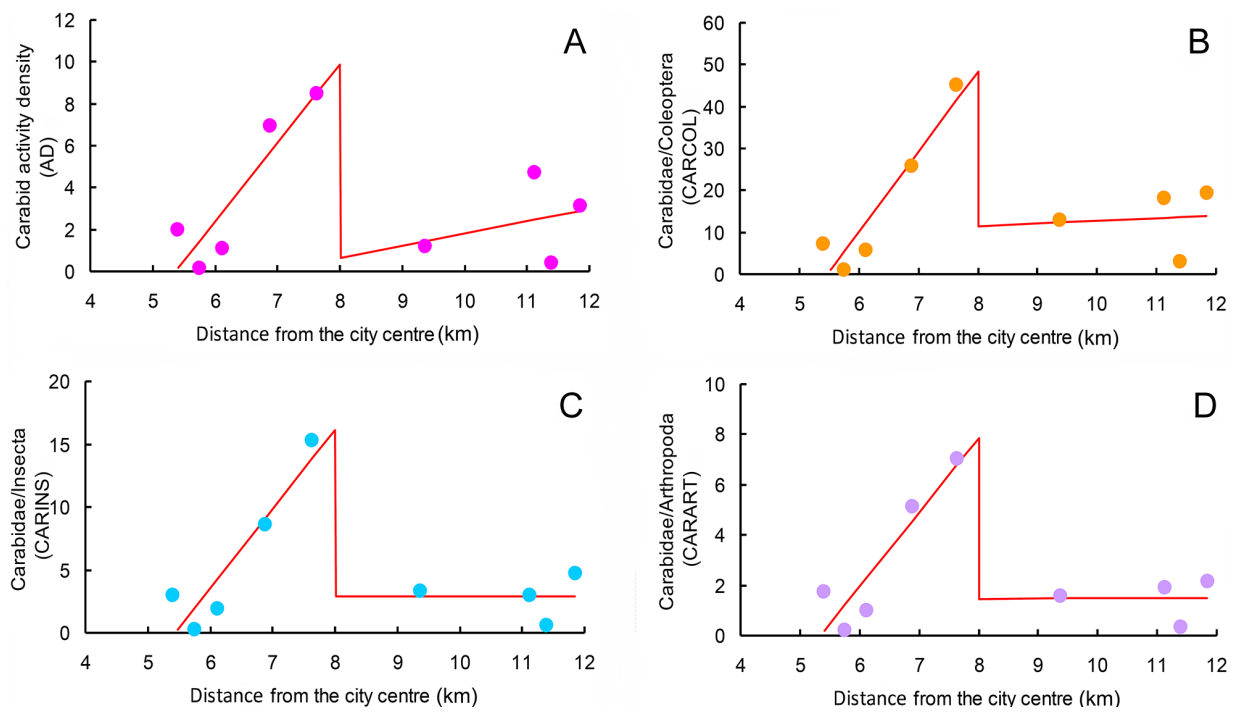

Fig. 3. Spatial variation in total activity density ( $\mathrm{AD}$, panel $\mathrm{A})$ and ratios of carabid beetles to total number of individual beetles (CARCOL, panel B), insects (CARINS, panel C), and arthropods (CARART, panel D) along the urban gradient ( $\mathrm{km}$ from the city centre). Red lines are fitted breakpoint regressions. Explained variances are as follows: $\mathrm{R}^{2}=0.720$ for for $\mathrm{AD}, \mathrm{R}^{2}=0.794$ for CARCOL, $\mathrm{R}^{2}=0.830$ for CARINS, and $\mathrm{R}^{2}=0.816$ for CARART 
will eventually eliminate all but the late-successional species. However, too much disturbance also reduces overall diversity by eliminating species unable of rapid recolonisation. Thus, there is an optimum degree of disturbance, which allows the maintenance of a maximum number of species. Therefore, the model proposed by PORTER et al. (2001), which focuses on spatial heterogeneity, is a modified version of ConNelL's (1978) intermediate disturbance hypothesis, already evoked to explain an intermediate peak in diversity (BLAIR \& Launer 1997, Germaine \& WaKeling 2001), and which is more based to temporal disturbance. It is also known that spatial diversity of urban habitats enhances species turnover (beta diversity) in plants and insects (ReBele 1994, Niemelä 1999). Thus it would be interesting, in the future, to see if the AD peak recorded in our study also corresponds to a peak in carabid species richness.

After the peak at about $8 \mathrm{~km}$ from the city centre, AD did not change significantly along the rest of the gradient (regression coefficient not significant). However, a certain positive trend is apparent. This suggests that, after decreasing sharply, AD tends to increase again, albeit slowly. This might suggest higher $\mathrm{AD}$ values in more natural areas, outside the urban-rural gradient, possibly because an enhanced naturalness of the environment promotes a more evenly distribution of species abundance values.

Carabid relative abundance (as expressed by their proportion to total beetles, insects, and arthropods) followed the same basic patterns as activity density. First, average carabid relative abundances did not vary significantly between the two sampling seasons, which means that carabid beetle contribution to the overall ground-dwelling beetle, insect and arthropod assemblages remains substantially the same. Second, carabid relative abundance followed the same spatial pattern of variation along the urban-rural gradient in the two sampling periods, which means that the relative contribution of carabids to total beetle, insect and arthropod abundance in soil-dwelling communities along the gradient does not change between seasons. Overall, these findings indicate that carabids play a prominent role in invertebrate community structure in both autumn and spring along the gradient.

Interestingly, our results are similar to the pattern that can be obtained by calculating the proportion of carabids to arthropods along the urban-rural gradient in London (Davis 1978). To this end, we used Davis' (1978) data of the number of carabids and number of arthropods trapped in London gardens at different distances from the city centre and applied a breakpoint regression approach (we omitted two sites that were clearly anomalous in having too few individuals of carabids and arthropods, respectively). We obtain that the proportion of carabids to arthropods (CARART) followed the same pattern observed in our study area: $y=(-2.734+2.254 \times D) \times(D \leq 20)+(35.130-0.696 \times$ $\mathrm{D}) \times(\mathrm{D}>20)$, with $\mathrm{R}^{2}=0.545$ (distance breakpoint set at $B=20 \mathrm{~km}$ ). 
As for activity density, carabid relative abundance (CARCOL, CARINS, and CARART) increased linearly from the beginning of the transect (i.e. near the city centre) to the middle, then declined sharply and remain low until the end of the gradient. This indicates that the relative importance of carabids in shaping communities of soil-dwelling invertebrates changes along the gradient, similarly to their activity density. This is not an obvious result. For example, carabid beetles might have a high activity density, but a low relative abundance, in a given site, and a low activity density, but a high relative abundance, in another - if carabids were abundant in the first and scarce in the second, but other beetles were much more abundant in the first site than in the second one.

The middle peak of carabid relative abundance (expressed as CARCOL, CARINS or CARART) can be explained by assuming that local habitat heterogeneity promotes their abundance. However, increasing urbanisation has detrimental effects more pronounced on these beetles than other members of the soil-dwelling animal communities, as indicated by the decrease in their relative abundance with decreasing distance to the city centre. This might be due to the relative increase in the abundance of other, possibly more generalist groups. For example, patterns of ant abundance across a gradient from a forest community to one associated with urban development in the Lake Tahoe Basin (USA) varied according to the functional groups (SANFORD et al. 2008). "Aerator ants" (which construct complex subterranean tunnels) had a humpshaped pattern peaking at the middle of the gradient, whereas "decomposer ants" (which construct their tunnels in woody debris) had a monotonic decrease, "compiler ants" (which construct thatch mounds on ground) had a slightly increasing monotonic pattern, and "generalist ants" had their lowest abundance in the middle of the gradient (SANFORD et al. 2008). These opposite patterns in aerator and generalist ants have been interpreted in relation to a disturbance. In general, the unimodal response in aerators can be considered the result of spatial heterogeneity created by ground disturbance from human activities and forest management, whereas the pattern in generalists can be considered a compensatory effect, due to the ability of generalists to perform some of the same ecosystem services provided by aerators when they are absent due to their higher sensitivity to land degradation. Similarly, we can hypothesise that the decreasing relative abundance in carabid beetles, which are mainly predators, at increasing urbanisation in our urban-rural gradient might be associated with an increase in the relative abundance of other functional groups in the total number of beetles, insects, or arthropods. Further research investigating spatial patterns of different functional groups along the urban-rural gradient considered in our study is needed to test this hypothesis. 


\section{CONCLUSIONS}

We found that carabid beetle activity density was similar in autumn and spring. This can be explained by assuming either a constant activity density over the year or the presence of two similar peaks. As already observed for various organisms in urban environments, we found that carabid activity density peaked in the middle of the urban-rural gradient. This supports the intermediate disturbance hypothesis, according to which moderate urbanisation may favour diversity by increasing habitat heterogeneity. Proportions of carabids to total beetle, insect or arthropod abundance peaked in the middle of the gradient, which indicates that intermediate urbanisation favours carabids more than most of the other taxa. Our findings regard cumulative activity density, with no distinction among species or functional groups. Further research is therefore needed to investigate how different functional groups, species richness, diversity and individual species activity density respond to the urban-rural gradient.

Acknowledgements - We are grateful to Dr. Fabrizio Piccari of the Appia Antica Regional Park for his support during fieldwork and data collection and to an anonymous reviewer for his/her comments on a previous version of the manuscript. This research has been partially funded by the Grant of Excellence Departments, MIUR-Italy (ARTICOLO 1, COMMI 314 - 337 LEGGE 232/2016).

\section{REFERENCES}

Adler, F. R. \& TANner, C. J. (2013): Urban ecosystems: ecological principles for the built environment. - Cambridge University Press, Cambridge, 357 pp.

Angold, P. G., Sadler, J. P., Hill, M. O., Pullin, A., Rushton, S., Austin, K., Small, E., Wood, B. \& Wadsworth, R. (2006): Biodiversity in urban habitat patches. - Science of the Total Environment 360: 196-204. https://doi.org/10.1016/j.scitotenv.2005.08.035

BLAIR, R. B. (1999): Birds and butterflies along an urban gradient: surrogate taxa for assessing biodiversity? - Ecological Applications 9: 164-170. https://doi.org/10.1890/10510761(1999)009[0164:BABAAU]2.0.CO;2

Blair, R. B. \& LAuner, A. E. (1997): Butterfly diversity and human land use: Species assemblages along an urban gradient. - Biological Conservation 80: 113-125. https://doi. org/10.1016/S0006-3207(96)00056-0

Den Boer, P. J. \& Den Boer-DaAnJe, W. (1990): On life history tactics in carabid beetles: are there only spring and autumn breeders? Pp. 247-258, In: SтоRк, N. E. (ed.): The role of ground beetles in ecological and environmental studies. Intercept, Andover.

Comandini, F. \& Vigna Taglianti, A. (1990): Phenology of Carabid Beetle Communities along an Altitudinal Transect in Central Italy. Pp. 389-391. In: Sтокк, N. E. (ed.): The Role of Ground Beetles in Ecological and Environmental Studies. Intercept, Andover. 
Brandmayr, P. \& Zetto, T. (1986): Phenology of Ground Beetles and its Ecological Significance in Some of the Main Habitat Types of Southern Europe. Pp. 195-220. In: DEN Boer, P. J., Luff, M. L., Mossakowski, F. \& Weber, F. (eds): Carabid Beetles - Their Adaptations and Dynamics. - Gustav Fischer, Stuttgart.

Brandmayr, P., Zetto, T. \& Pizzolotto, R. (2005): I Coleotteri Carabidi per la valutazione ambientale e la conservazione della biodiversità. Manuale operativo. Manuali e Linee guida 34/2005. - APAT - Agenzia per la protezione dell'ambiente e per i servizi tecnici, Roma, 240 pp. [in Italian]

Buccomino, G. \& Stanisci, A. (2000): Contributo alla conoscenza floristica della Valle della Caffarella (Roma). - Informatore botanico italiano 32: 3-15.

Celesti Grapow, L. \& Fanelli, G. (1993): The vanishing landscape of the Campagna Romana. - Landscape and Urban Planning 24: 69-76. https://doi.org/10.1016/01692046(93)90085-R

Ceschin, S., Cutini, M. \& Caneva, G. (2006): Contributo alla conoscenza della vegetazione delle aree archeologiche romane (Roma). - Fitosociologia 43: 97-139.

Connell, J. H. (1978): Diversity in tropical rain forests and coral reefs. - Science 199: 13021310. https://doi.org/10.1126/science.199.4335.1302

Davis, B. N. K. (1978): Urbanisation and the diversity of insects. Pp. 126-138. In: Mound, L. A. \& WALOFf, N. (eds): Diversity of insect faunas. - Symposia of the Royal Entomological Society of London, 9. Blackwell Scientific Publications, London,

Di Pietro, S., Mantoni, C. \& Fattorini, S. (2020): Influence of urbanization on the avian species-area relationship: insights from the breeding birds of Rome. Urban Ecosystems https://doi.org/10.1007/s11252-020-01081-4

Eldredge, N. \& Horenstein, S. (2014): Concrete jungle. New York city and our last best hope for a sustainable future. - University of California Press, Oakland, 288 pp.

Eötvös, C. B., LöveI, G. L. \& Magura, T. (2020): Predation pressure on sentinel insect prey along a riverside urbanization gradient in Hungary. - Insects 11: 97. https://doi. org/10.3390/insects11020097

Fanfani, A., Manes, F., Moretti, V., Ranazzi, L. \& Salvati, L. (2014): Vegetation, precipitation and demographic response of a woodland predator: Tawny Owl Strix aluco as an indicator of soil aridity in Castelporziano forest. - Rendiconti Lincei. Scienze Fisiche e Naturali 26: 391-397. https://doi.org/10.1007/s12210-015-0392-7

FATTORINI, S. (2011): Insect extinction by urbanization: a long term study in Rome. - Biological Conservation 144: 370-375. https://doi.org/10.1016/j.biocon.2010.09.014

Fattorini, S. (2019): Ecologia urbana. - Ediesse, Roma, 304 pp.

Fattorini, S. \& Galassi, D. M. P. (2016): Role of urban green spaces for saproxylic beetle conservation: a case study of tenebrionids in Rome, Italy. - Journal of Insect Conservation 20: 737-745. https://doi.org/10.1007/s10841-016-9900-z

Forman, R. T. (2014): Urban ecology: science of cities. - Cambridge University Press, Cambridge, $476 \mathrm{pp}$.

French, B. W., Elliott, N. C., Berberet, R. C. \& Burd, J. D. (2001): Effects of riparian and grassland habitats on ground beetle (Coleoptera: Carabidae) assemblages in adjacent wheat fields. - Environmental Entomology 30: 225-234. https://doi.org/10.1603/0046225X-30.2.225

Germaine, S. S. \& WAKeling, B. F. (2001): Lizard species distributions and habitat occupation along an urban gradient in Tucson, Arizona, USA - Biological Conservation 97: 229-237. https://doi.org/10.1016/S0006-3207(00)00115-4

Holland, J. M. (2002): The agroecology of carabid beetles. - Intercept, Andover, 356 pp. 
HŮRKA, K. (1986): The developmental type of Carabidae in the temperate zone as a taxonomic character. Pp. 187-194. In: Den Boer, P. J., Luff, M. L., Mossakowski, F. \& WeBER, F. (eds): Carabid beetles - Their adaptations and dynamics. - Gustav Fischer, Stuttgart.

Hammer, Ø, Harper, D. A. T. \& Ryan, P. D. (2001): PAST - PAlaeontological STatistics. Palaeontologia Electronica 4: 1-9.

JonEs, E. L. \& LeATHER, S. R. (2012): Invertebrates in urban areas: a review. - European Journal of Entomology 109: 463-478. https://doi.org/10.14411/eje.2012.060

Lafage, D., Secondi, J., Georges, A. \& Bouzillé, J. B. (2014): Satellite-derived vegetation indices as surrogate of species richness and abundance of ground beetles in temperate floodplains. - Insect Conservation and Diversity 7: 327-333. https://doi.org/10.1111/ icad.12056

Lucchese, F. \& Pignatti, E. (2009): La vegetazione nelle aree archeologiche di Roma e della Campagna Romana - Quaderni di Botanica ambientale e applicata 20: 3-89.

McDonald, R. I., Marcotullio, P. J. \& Güneralp, B. (2013): Urbanization and global trends in biodiversity and ecosystem services. Pp. 31-52. In: Elmqvist, T., Fragkias, M., Goodness, J., Güneralp, B., Marcotullio, P. J., McDonald, R. I., Parnell, S., Schewenius, M., Sendstad, M., Seto, K. C. \& Wilkinson, C. (eds): Urbanization, biodiversity and ecosystem services: Challenges and opportunities: A global assessment. - Springer, Dordrecht.

McDonnell, M. J. \& Hahs, A. (2008): The use of gradient analysis studies in advancing our understanding of the ecology of urbanizing landscapes: Current status and future directions. - Landscape Ecology 23: 1143-1155. https://doi.org/10.1007/s10980-008-9253-4

McKinney, M. L. (2002): Urbanization, biodiversity, and conservation: The impacts of urbanization on native species are poorly studied, but educating a highly urbanized human population about these impacts can greatly improve species conservation in all ecosystems. - Bioscience 52: 883-890. https://doi.org/10.1641/00063568(2002)052[0883:UBAC]2.0.CO;2

McKinnEY, M. L. (2006): Urbanization as a major cause of biotic homogenisation. - Biological Conservation 127: 247-260. https://doi.org/10.1016/j.biocon.2005.09.005

McKinney, M. L. (2008): Effects of urbanization on species richness: a review of plants and animals. - Urban Ecosystems 11: 161-176. https://doi.org/10.1007/s11252-007-0045-4

New, T. R. (2015): Insect conservation and urban environments. - Springer, New York, 244 pp. https://doi.org/10.1007/978-3-319-21224-1

Niemelä, J., Kotze, J., Ashworth, A., Brandmayr, P., Desender, K., New, T., Penev, L., SAmways, M. \& SPENCE J. (2000): The search for common anthropogenic impacts on biodiversity: a global network. Journal of Insect Conservation 4: 3-9. https://doi. org/10.1023/A:1009655127440

Niemelä, J., Kotze, D. J. , Venn, S., Penev, L., Stoyanov, I., Spence, J., Hartley, D. \& Montes DE OcA, E. (2002): Carabid beetle assemblages (Coleoptera, Carabidae) across urbanrural gradients: an international comparison. - Landscape Ecology 17: 387-401. https:// doi.org/10.1023/A:1021270121630

Niemelä, J. \& Kotze, D. J. (2009): Carabid beetle assemblages along urban to rural gradients: a review. - Landscape and Urban Planning 92: 65-71. https://doi.org/10.1016/j. landurbplan.2009.05.016

Niemelä, J. (1999): Ecology and urban planning. - Biodiversity and Conservation 8: 119-131. https://doi.org/10.1023/A:1008817325994

Porter, E. E., Forschner, B. R. \& Blair, R. B. (2001): Woody fragmentation and canopy fragmentation along a forest-to-urban gradient. - Urban Ecosystems 5:131-151. https:// doi.org/10.1023/A:1022391721622 
PaArman, W. (1970): Untersuchungen über die Jahresrhythmik von Laufkäfern (Coleoptera, Carabidae) in der Cyrenaika (Libyen, Nordafrika). - Oecologia 5: 325-333. https://doi.org/10.1007/BF00815498

Pizzolotto, R., Mazzei, A., Bonacci, T., Scalercio, S., Iannotta, N., Brandmayr, P. (2018): Ground beetles in Mediterranean olive agroecosystems: Their significance and functional role as bioindicators (Coleoptera, Carabidae). - PLoS ONE 13: e0194551. https:// doi.org/10.1371/journal.pone.0194551

Purtauf, T., Dauber, J. \& Wolters, V. (2005): The response of carabids to landscape simplification differs between trophic groups. - Oecologia 142:458-464. https://doi. org/10.1007/s00442-004-1740-y

Rebele, F. (1994): Urban ecology and special features of urban ecosystems. - Global Ecology and Biogeography Letters 4: 173-187. https://doi.org/10.2307/2997649

Salvati, L., Venanzoni, G., Serra, P. \& Carlucci, M. (2016): Scattered or polycentric? Untangling urban growth in three southern European metropolitan regions through exploratory spatial data analysis. - The Annals of Regional Science 57: 1-29. https://doi. org/10.1007/s00168-016-0758-5

Salvati, L., Ciommi, M. T., Serra, P. \& Chielli, F. M. (2019): Exploring the spatial structure of housing prices under economic expansion and stagnation: The role of socio-demographic factors in metropolitan Rome, Italy. - Land Use Policy 81: 143-152. https://doi. org/10.1016/j.landusepol.2018.10.030

SAnford, M. P., Manley , P. N. \& Murphy, D. D. (2008): Effects of urban development on ant communities: implications for ecosystem services and management. - Conservation Biology 23: 131-141. https://doi.org/10.1111/j.1523-1739.2008.01040.x

STATSoft Inc. (2001): STATISTICA (data analysis software system), version 6. Computer program manuals. - Tulsa, USA, http://www.statsoft.com

Thiele, H.-U. (1977): Carabid beetles in their environments. - Springer Verlag, Berlin. https:// doi.org/10.1007/978-3-642-81154-8

Worldwatch Institute (2007): State of the World 2007: our urban future. - W. W. Norton \& Company Inc., New York, 288 pp.

Received March 13, 2020, accepted December 6, 2020, published December 28, 2020 